\title{
Error Cost Escalation Through the Project Life Cycle
}

\begin{abstract}
It is well known that the costs to fix errors increase as the project matures, but how fast do those costs build? A study was performed to determine the relative cost of fixing errors discovered during various phases of a project life cycle. This study used three approaches to determine the relative costs: the bottom-up cost method, the total cost breakdown method, and the top-down hypothetical project method. The approaches and results described in this paper presume development of a hardware/software system having project characteristics similar to those used in the development of a large, complex spacecraft, a military aircraft, or a small communications satellite.

The results show the degree to which costs escalate, as errors are discovered and fixed at later and later phases in the project life cycle. If the cost of fixing a requirements error discovered during the requirements phase is defined to be 1 unit, the cost to fix that error if found during the design phase increases to $3-8$ units; at the manufacturing/build phase, the cost to fix the error is $7-16$ units; at the integration and test phase, the cost to fix the error becomes 21 78 units; and at the operations phase, the cost to fix the requirements error ranged from 29 units to more than 1500 units.
\end{abstract}

\section{Introduction}

We know that the cost to fix errors increases as a project matures - that it will cost more to fix a requirements error after the product is built than it would if the requirements error was discovered during the requirements phase of a project. So how important is it to the bottom-line to find errors as early as possible - putting increased emphasis on systems engineering tasks in the early stages of the project life cycle? Especially when schedule urgencies push the project to rush through definition and start cutting metal? Increased emphasis on finding errors early in the project life cycle means spending more time and a larger percentage of project costs in the definition phases of a project - more than is usually allocated to the early phases.

\section{Background}

Many published papers, articles, and books (cited in the following sub-sections) provide information regarding the "value" of systems engineering and quantitative software cost factors, but few sources in the published literature define system cost factors. When relative cost-to-fix numbers are published, it is difficult to discern the methods used to produce the results.

Cost Factors. In this paper, we will often refer to the term "cost factors." It is a term used in many of the previous studies discussing the costs of errors in software systems, and is central to the methodologies we used to analyze generic systems error costs. Cost factors represent normalized costs to fix an error. These factors may be used as a "yardstick" to measure or predict the cost to fix errors in different projects.

Software Cost Factors. Barry Boehm performed some of the first cost studies to determine - by software life cycle phase - the cost factors associated with fixing errors. Finding and fixing a 
software problem after delivery can be upwards of 100 times more expensive than finding it and fixing it during the requirements and early design phases. Late corrections involve a much more formal change approval and control process, and a much more extensive activity to revalidate the correction. The relative cost to fix a software error is shown below in Figure 1 [Boehm, 1981].

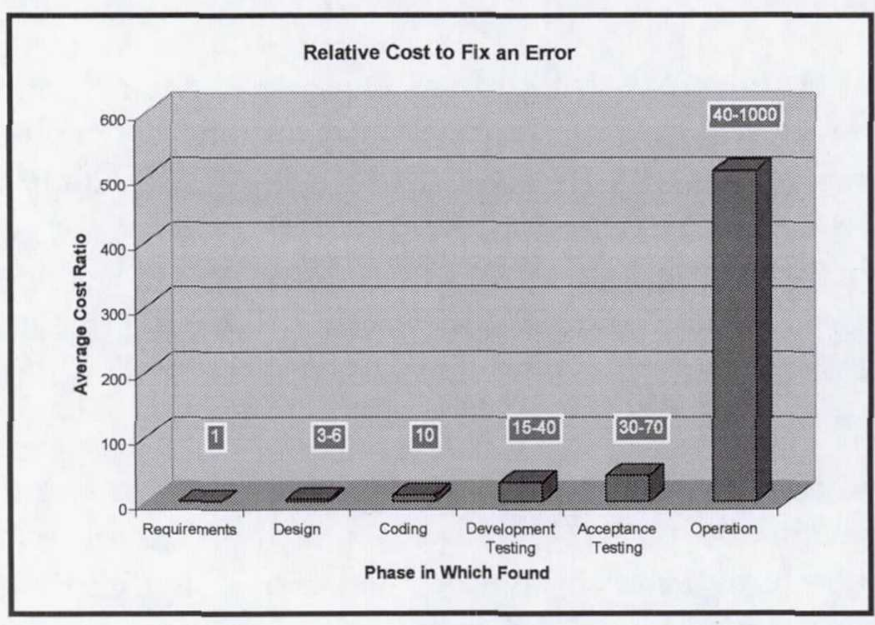

\section{Figure 1. Relative Cost to Fix Software Errors per Life Cycle Phase}

Many studies have been performed to determine the software error costs factors [Rothman, 2002], [Pavlina, 2003], [McGibbon, 2003], [Cigital, 2003]. Error cost escalation is often used to justify expenditures for software engineering process improvements and software quality assurance activities [Schneider, Martin, \& Tsai, 1992], [Mortice Kern Systems Inc., 2001]. The cost data has been normalized to determine the software error cost factors for each study, along with the overall mean and median values for each life cycle phase, as shown in Table 1.

\begin{tabular}{|l|l|l|l|l|}
\hline Source & \multicolumn{4}{|c|}{ Phase Requirements Issue Found } \\
\hline & Requirements & Design & Code & Test \\
\hline [Boehm, 1981] & 1 & 5 & 10 & 50 \\
\hline$[$ Hoffman, 2001] & 1 & 3 & 5 & 37 \\
\hline$[$ Cigital, 2003] & 1 & 3 & 7 & 51 \\
\hline [Rothman, 2000] & & 5 & 33 & 75 \\
\hline [Rothman, 2000] Case B & & & 10 & 40 \\
\hline [Rothman, 2000] Case C & & & 10 & 40 \\
\hline [Rothman, 2002] & 1 & 20 & 45 & 250 \\
\hline [Pavlina, 2003] & 1 & 10 & 100 & 1000 \\
\hline [McGibbon, 2003] & & 5 & & 50 \\
\hline Mean & $\mathbf{1}$ & $\mathbf{7 . 3}$ & $\mathbf{2 5 . 6}$ & $\mathbf{1 7 7}$ \\
\hline Median & $\mathbf{1}$ & $\mathbf{1 0}$ & $\mathbf{5 0 . 5}$ \\
\hline
\end{tabular}

Table 1: Normalized Cost-to-Fix Estimates 
System Cost Factors. The only known published information on systems cost factors was found in a book on designing cost-effective space missions [Cloud, Giffen, Larson, and Swan, 1999]. These systems cost factors, shown in Table 2, represent the costs of fixing errors in electronics hardware. The costs are referenced without any description of the approach or method used to generate the comparative cost numbers, therefore it is difficult to discuss similarities and differences between the costs in Table 2 and the results of this paper.

\begin{tabular}{|l|l|}
\hline Phase that Change Occurs & Resulting Cost \\
\hline Product Design & $\$ 1,000$ \\
\hline Product Testing & $\$ 10,000$ \\
\hline Process Design & $\$ 100,000$ \\
\hline Low-Rate Initial Production & $\$ 1,000,000$ \\
\hline Final Production/Distribution & $\$ 10,000,000$ \\
\hline
\end{tabular}

Table 2: Systems Cost Factors

\section{Life Cycle Phases}

Figure 2 maps the five life cycle phases, used in this paper, to the NASA project life cycle flow, and to the NASA and Department of Defense (DoD) acquisition phases. Major control gates, i.e. technical maturity milestones, are also shown in Figure 2. The NASA Systems Engineering Life Cycle [NASA SE Handbook, 1995] was used to categorize, by phase, the error discovery point.

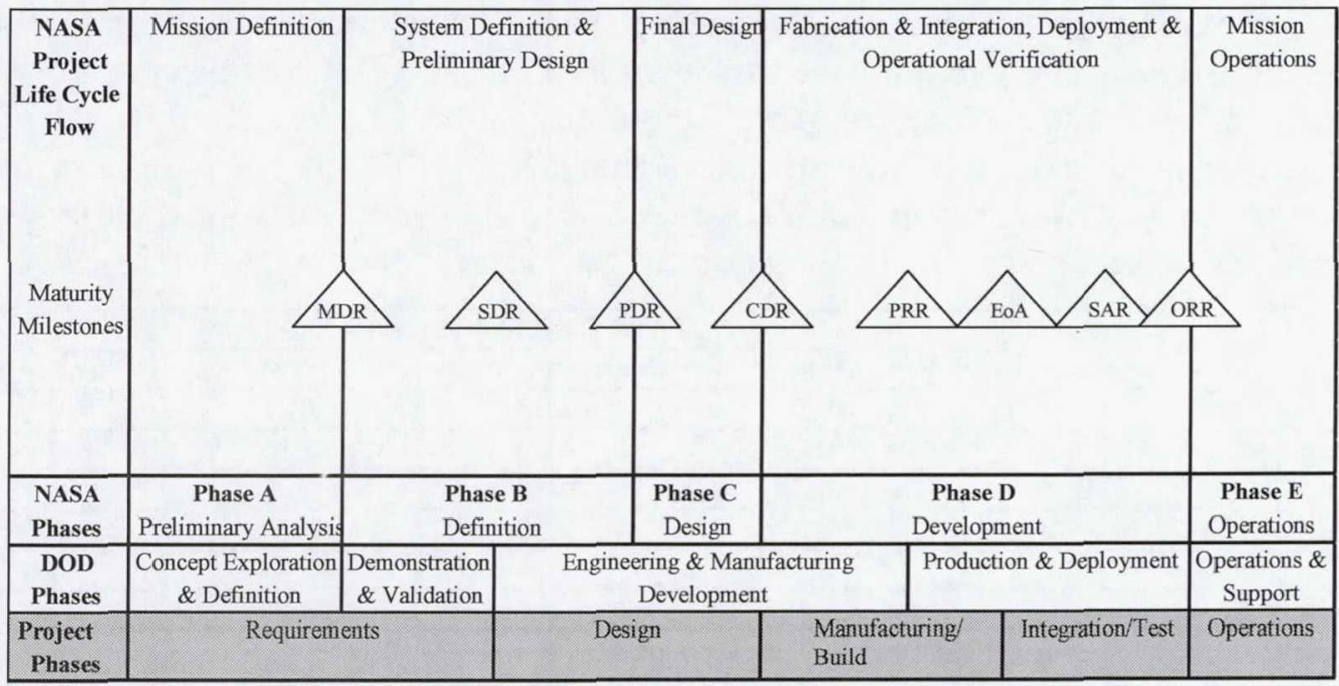

Figure 2. Project Phases in Relation to NASA and DoD Phases

\section{Method 1 - Bottom-Up Cost}

Description. The bottom-up method of determining the cost to fix errors found in different phases of the life cycle is derived from the most detailed form of cost estimation. The costs are gathered from every major discipline including all engineering groups, quality, contracts, vendors, logistics, program office, test, and many more. These costs and the schedule to complete the tasks are then rolled up into a total cost to fix the error and a total project schedule. Given the rolled up costs for several spacecraft modifications that were required to fix errors, the overall error cost rates were estimated for each individual life cycle phase based on the bottomup costs. 
Methodology. This approach used the cost data from several spacecraft modifications. The cost data came in the form of total costs per modification per fiscal year and included a schedule for the effort to complete the modifications. The activities throughout the entire project schedule were consolidated into the five life cycle phases. The tasks were mapped to the suitable life cycle phase, using the NASA Systems Engineering (SE) Handbook as a guide. For example, when a structures engineer included hours and schedule to recalculate the loads for a particular fix that added weight, these costs were included in the design life cycle phase. When the test engineer stated additional tests would have to be performed, that task was included within the test phase. Every task included within the bottom-up approach was analyzed and checked against the NASA SE Handbook and placed within the appropriate life cycle phase.

Assumptions. For each modification, the tasks required to fix the error were assigned to the appropriate life cycle phase. For the modification cost data, a percentage of individual fiscal year labor and material costs was assigned based on the extent that each life cycle phase overlapped that particular fiscal year. For example, if $80 \%$ of a project's fiscal schedule was requirements tasks and the other $20 \%$ was design tasks, the fiscal year costs were separated accordingly. Once this was accomplished for all fiscal years, the life cycle phases were summed by adding their assigned percentage costs across the entire project.

Analysis. Costs per fiscal year for each of the five projects were known and spread among the active life cycle phases within that fiscal year based on the percentage of work for each phase in that year. Costs were summed across the years for each life cycle phase to determine the total cost percentage for each life cycle phase, as shown in Table 3 . The cost percentage to fix the error for each phase is averaged across the different errors. Cost factors are then calculated by dividing the average cost to fix the error in each phase by the cost to fix the error in the requirements phase, which results in cumulative costs per life cycle phase for each project. The average/ relative cost factors per life cycle phase for each project are also shown in Table 3 .

\begin{tabular}{|l|c|c|c|c|c|}
\cline { 2 - 6 } \multicolumn{1}{c|}{} & \multicolumn{5}{c|}{ \% Total Cost Per Phase } \\
\cline { 2 - 6 } \multicolumn{1}{c|}{} & Requirements & Design & Manufacturing & Test & Production \\
\hline Project 1 & 0.01 & 0.21 & 0.33 & 0.31 & 0.14 \\
\hline Project 2 & 0.02 & 0.36 & 0.22 & 0.16 & 0.24 \\
\hline Project 3 & 0.07 & 0.34 & 0.13 & 0.08 & 0.38 \\
\hline Project 4 & 0.06 & 0.17 & 0.33 & 0.14 & 0.30 \\
\hline Project 5 & 0.01 & 0.19 & 0.24 & 0.13 & 0.43 \\
\hline
\end{tabular}

\begin{tabular}{|l|c|c|c|c|c|}
\cline { 2 - 6 } \multicolumn{1}{c|}{} & \multicolumn{5}{c|}{ \% Cumulative Cost Per Phase } \\
\cline { 2 - 6 } \multicolumn{1}{c|}{} & Requirements & Design & Manufacturing & Test & Production \\
\hline Project 1 & 0.01 & 0.22 & 0.55 & 0.86 & 1.00 \\
\hline Project 2 & 0.02 & 0.38 & 0.60 & 0.76 & 1.00 \\
\hline Project 3 & 0.07 & 0.41 & 0.54 & 0.62 & 1.00 \\
\hline Project 4 & 0.06 & 0.23 & 0.56 & 0.70 & 1.00 \\
\hline Project 5 & 0.01 & 0.20 & 0.44 & 0.57 & 1.00 \\
\hline Average & 0.03 & 0.29 & 0.54 & 0.70 & 1.00 \\
\hline \hline Relative & 1 & 8 & 16 & 21 & 29 \\
\hline
\end{tabular}

\section{Table 3: Method 1 Percentage / Cumulative Cost Per Phase and Relative Cost Factors per Phase}

Results. The comparison of Method 1 cost factors to the software cost factors is shown in Table 4. 


\begin{tabular}{|c|c|c|}
\hline & Method 1 Cost Factors & Software Cost Factors \\
\hline Requirements & $1 \mathrm{X}$ & $1 \mathrm{X}$ \\
\hline Design & $8 \mathrm{X}$ & $5 \mathrm{X}-7 \mathrm{X}$ \\
\hline Build & $16 \mathrm{X}$ & $10 \mathrm{X}-26 \mathrm{X}$ \\
\hline Test & $21 \mathrm{X}$ & $50 \mathrm{X}-177 \mathrm{X}$ \\
\hline Operations & $29 \mathrm{X}$ & $100 \mathrm{X}-1000 \mathrm{X}$ \\
\hline
\end{tabular}

\section{Table 4: Comparison of Method 1 and Software Cost Factors}

The correlation between the cost factors generated by Method 1 for a large spacecraft project and the software cost factors suggests that life cycle changes have similar cost effects on hardware/software systems and software-only systems. Based on the results from this method, it can be concluded that hardware fixes are more forgiving in terms of costs when compared to software fixes. The cost factors are understandingly slightly higher in the earlier design phase possibly because hardware design is more costly than software design. In contrast, the later phases of build, test and operations show surprisingly lower relative cost factors than those generated from software studies.

\section{Method 2 - Total Costs Breakdown}

Description. With first hand knowledge of the phase in which an error occurred and averaging multiple changes for each phase, a cost factor escalation can be calculated between phases. The data used for this method came from a major aircraft design, build, flight test and operations program valued in the billions of dollars. The total number of changes utilized was greater than 3300. These changes encompassed two decades of the aircraft project life cycle and included pre-design, design, build, flight test, and operation changes.

Methodology. A data reduction exercise was conducted to reduce the 3300 original changes into the 231 changes that were used in the calculations. The 3300 errors were first reduced to 1427 hardware-impacted changes by deleting changes that had the following characteristics: Software only; Study only; Support Equipment Only, Ground, Test, or Foreign Object Damage; Total unknown changes; or Changes to facilities. The 1427 hardware-impacted changes were further reduced to 231 true hardware errors by deleting the changes that had the following characteristics: Pure Upgrades or improvements (not fixes); Documentation Only (Parts plan, Test Plan, etc.); Subcontractor Labor only (Level of Effort); or Changes that only impacted individual aircraft.

These 231 remaining errors were then broken down into their respective SE life cycle phase. Their average costs were tabulated and a one and two standard deviation was performed. Using the average and expanding that value out to include two deviations, a range was found that was surprisingly similar to the costs to fix software errors. The list of 231 hardware errors was reviewed and evaluated to identify which life cycle phase the error was discovered. This categorization was performed using the author's personal knowledge of these errors, the error description and/or title, and through interviews with the engineers involved.

Once the errors were categorized into one of the five SE life cycle phases, most of the errors in a particular phase could be placed into categories. These categories are shown below with their respective life cycle phase. Requirement errors were mostly: Part Number errors; Reference designator errors; or Label/marking errors. Design errors dealt with: Cable Routing; 
Material changes for corrosion; Deletion of misc. hardware, un-needed seals, etc.; or Smoothness issues prior to manufacturing. Manufacturing errors were mainly: Changes to hardware in order to eliminate obstructions; Interference issues; Shimming requirements; or Hardware replacements. Testing errors included: Performance issues; Qualification test failures; or Requalification changes. Operations errors were found to be: Large errors found after delivery to the field or Crew requested fixes.

Assumption. The Total Cost Breakdown method relied on facts and data obtained from personal knowledge of the major aircraft program, which was the subject of Method 2. Knowing when the aircraft entered flight test and was delivered to operations helped place errors within a certain life cycle phase. For example, if the aircraft had not been delivered yet and an error was discovered during flight, the error most likely occurred during the test phase. The earlier errors that occurred prior to the start of design were assumed to be errors that could be placed in the requirements phase. If manufacturing had not begun, it was assumed that the error belonged to one of the first two phases. Once the flight test milestone was passed, all errors were placed into the operations phase.

Analysis. The remaining 231 changes were assigned to the appropriate life cycle phase (requirements, design, build, test, or operations). Table 5 shows the distribution of the 231 changes per life cycle phase. In the tables $6 \& 7$ below, the errors contained in the 1 and 2 deviations columns are those errors that are contained within 1 and 2 standard deviations from the mean.

\begin{tabular}{|c|c|c|c|}
\hline & All Errors & 1 Deviation & 2 Deviations \\
\hline Requirements & 66 & 57 & 61 \\
\hline Design & 61 & 49 & 55 \\
\hline Build & 41 & 35 & 35 \\
\hline Test & 21 & 19 & 20 \\
\hline Operations & 42 & 36 & 39 \\
\hline TOTAL & 231 & 196 & 210 \\
\hline
\end{tabular}

Table 5: Numbers of Errors per Life Cycle Phase

\begin{tabular}{|c|c|c|c|}
\hline & All Errors & 1 Deviation & 2 Deviations \\
\hline Requirements & $\$ 667-\$ 209,504$ & $\$ 667-\$ 40,038$ & $\$ 667-\$ 59,022$ \\
\hline Design & $\$ 1,880-\$ 306,036$ & $\$ 1,880-\$ 131,104$ & $\$ 1,880-\$ 192,382$ \\
\hline Build & $\$ 54,830-\$ 1,511,365$ & $\$ 54,830-\$ 483,694$ & $\$ 54,830-\$ 483,694$ \\
\hline Test & $\$ 50,046-\$ 12,383,000$ & $\$ 50,046-\$ 1,941,787$ & $\$ 50,046-\$ 2,926,000$ \\
\hline Operations & $\$ 480,214-\$ 36,739,000$ & $\$ 480,214-\$ 4,553,577$ & $\$ 480,214-\$ 9,401,506$ \\
\hline
\end{tabular}

Table 6: Cost Ranges of Errors per Life Cycle Phase

\begin{tabular}{|c|c|c|c|c|}
\hline & Average Cost & Standard Deviation & 1 Deviation & 2 Deviation \\
\hline Requirements & $\$ 22,632$ & $\$ 31,510$ & $\$ 54,142$ & $\$ 85,652$ \\
\hline Design & $\$ 87,832$ & $\$ 70,191$ & $\$ 158,023$ & $\$ 228,214$ \\
\hline Build & $\$ 354,808$ & $\$ 381,953$ & $\$ 736,761$ & $\$ 1,118,714$ \\
\hline Test & $\$ 1,370,888$ & $\$ 2,638,785$ & $\$ 4,009,673$ & $\$ 6,648,458$ \\
\hline Operations & $\$ 3,558,215$ & $\$ 6,207,912$ & $\$ 9,766,127$ & $\$ 15,974,039$ \\
\hline
\end{tabular}

Table 7: Average Cost and Standard Deviations per Life Cycle Phase

Results. The data in Table 8 was then normalized into cost factors to compare it to the software 
cost factors and the other method's cost factors in this paper.

\begin{tabular}{|c|c|}
\hline & $\begin{array}{c}\text { Average to 2 Deviation Cost } \\
\text { Factors }\end{array}$ \\
\hline Requirements & $1 \mathrm{X}$ \\
\hline Design & $3 \mathrm{X}-4 \mathrm{X}$ \\
\hline Build & $13 \mathrm{X}-16 \mathrm{X}$ \\
\hline Test & $61 \mathrm{X}-78 \mathrm{X}$ \\
\hline Operations & $157 \mathrm{X}-186 \mathrm{X}$ \\
\hline
\end{tabular}

Table 8: Method 2 Cost Factors per Life Cycle Phase

\section{Method 3 - Top-Down Hypothetical Project}

Description. The top-down hypothetical project method models the escalation of error costs using the architecture of a hypothetical aerospace project and hypothetical errors. The errors are modeled such that they are discovered in each phase of the project and affect each of the major satellite systems. Using these errors, a set of representative values for the cost to fix errors discovered at different phases in the project life cycle was calculated. The hypothetical project used in this analysis is a small communications satellite. The systems modeled were selected to be representative of the kinds of systems present in similar satellites.

Methodology. The methodology consists of two parts. First, the hypothetical system was modeled such that the cost to complete the work in each life cycle phase and for each subsystem in the satellite was known. Next, errors were formulated along with the cost to fix the error expressed as a percentage of the work already performed on the affected subsystem.

Assumptions. This method assumes that the satellite architecture is a reasonable representation of this type of space project. Second, this method assumes that the Cost Estimating Relationship used is valid for this type of satellite architecture. Third, this method assumes that the cost spreader function beta curve and the constants selected are applicable to this type of satellite. Fourth, this method assumes that the projects used to derive the life cycle phases are representative of the development of this type of satellite system. Finally, the estimation of the costs to fix each error is based heavily on the author's experience.

Satellite Cost Model. Satellite costs were modeled using estimates of the costs for each satellite subsystem and life cycle phase. Subsystem costs were determined using the Cost Estimating Relationships (CER) developed by Larson and Wertz. The specific CER used is for unmanned spacecraft, and has ranges that apply to the example satellite chosen. [Larson and Wertz, 1993]. Costs per life cycle phase were modeled using the cost spreader function beta curve developed by NASA to spread costs over time. The combined subsystem and life cycle costs were derived by multiplying the percentage cost for each subsystem by the percentage cost for each phase. The subsystem and lifecycle costs are shown in the table 9 below. 


\begin{tabular}{|l|c|}
\hline Subsystem & Cost \\
\hline \hline Antenna & $2.57 \%$ \\
\hline Communications Electronics & $13.99 \%$ \\
\hline Structures/Thermal & $10.50 \%$ \\
\hline Command and Data Handling & $6.97 \%$ \\
\hline Attitude Determ. & $19.24 \%$ \\
\hline Attitude Control & $5.86 \%$ \\
\hline Electrical Power & $13.46 \%$ \\
\hline Apogee Kick Motor & $0.95 \%$ \\
\hline Program Management & $5.29 \%$ \\
\hline Systems Engineering & $10.59 \%$ \\
\hline Product Assurance & $5.29 \%$ \\
\hline Test and Evaluation & $5.29 \%$ \\
\hline
\end{tabular}

\begin{tabular}{|l|c|}
\hline Life Cycle & Cost \\
\hline \hline Requirements & $1.48 \%$ \\
\hline Design & $4.01 \%$ \\
\hline Manufacture & $3.85 \%$ \\
\hline Test & $17.77 \%$ \\
\hline Operations & $72.88 \%$ \\
\hline
\end{tabular}

Table 9: Subsystem and Life Cycle Costs

Error Analysis. Each error is modeled to occur in the requirements phase and directly affects only one subsystem and which involves a failure to correctly develop the project requirements for one of the subsystems. In addition, if the error is not detected prior to the Operations phase, it will result in a loss of the mission. Although each error is hypothetical, the effects of each error were estimated using the guidelines developed by Larson and Wertz and the NASA Systems Engineering Handbook. The effort required to fix the errors was estimated in two ways. Some of the effort is based on detailed breakdowns of the tasks required to task fix the error. Other errors assume a fixed percentage of the effort is repeated, incremented from $10 \%$ to $30 \%$ to $50 \%$. The effort to fix the error is estimated as a percentage of work already performed for that subsystem (percent that must be repeated), based on the phase at which the error is discovered. Error descriptions are shown below in table 10.

\begin{tabular}{|c|l|}
\hline Error number & \multicolumn{1}{|c|}{ Error Description } \\
\hline \hline $1-6$ & Detailed Error Task Breakdown \\
\hline $7-12$ & $30 \%$ Repeat with no Interface Effects \\
\hline $13-18$ & $10 \%$ Repeat with no Interface Effects \\
\hline $19-24$ & $50 \%$ Repeat with no Interface Effects \\
\hline
\end{tabular}

Table 10: Error Descriptions

Error Relative Cost. Using the MATLAB model, costs to fix each error were calculated. The costs for each life cycle phase were then averaged. The relative cost to fix errors per phase is calculated by dividing the cost to fix the error in each phase by the cost to fix the error in the requirements phase

Results. This model provides insight into the reasons for error cost escalation. It can be seen that as the project proceeds, the amount of work performed - and hence the cost - increases. Another important point is the effect of an error on interfaces with other subsystems. Errors can dramatically increase in cost if the errors affect other subsystems. This method has numbers for the operations phase that are significantly greater than those in the other methods. This difference is due primarily to the fact that the satellite cannot be serviced or repaired once it enters the operations phase. Table 11 compares the top-down hypothetical project life cycle cost factors to the software cost factors. 


\begin{tabular}{|l|c|c|}
\hline & Hypo Proj Cost Factors & Software Cost Factors \\
\hline \hline Requirements & $1 \mathrm{X}$ & $1 \mathrm{X}$ \\
\hline Design & $4 \mathrm{X}$ & $5 \mathrm{X}-7 \mathrm{X}$ \\
\hline Build & $7 \mathrm{X}$ & $10 \mathrm{X}-26 \mathrm{X}$ \\
\hline Test & $28 \mathrm{X}$ & $50 \mathrm{X}-177 \mathrm{X}$ \\
\hline Requirements & $1 \mathrm{X}$ & $1 \mathrm{X}$ \\
\hline
\end{tabular}

Table 11: Cost Factors

\section{Overall Results and Interpretations}

Table 12 compares the cost factors determined by each of the three methods. While the results are similar in many respects, there are also differences between the results. This section will discuss some of those similarities and potential reason for the dissimilarities.

\begin{tabular}{|l|c|c|c|}
\hline & $\begin{array}{c}\text { Method 1 } \\
\text { Cost Factors }\end{array}$ & $\begin{array}{c}\text { Method 2 } \\
\text { Cost Factors }\end{array}$ & $\begin{array}{c}\text { Method 3 } \\
\text { Cost Factors }\end{array}$ \\
\hline Requirements & $1 \mathrm{X}$ & $1 \mathrm{X}$ & $1 \mathrm{X}$ \\
\hline Design & $8 \mathrm{X}$ & $3 \mathrm{X}-4 \mathrm{X}$ & $4 \mathrm{X}$ \\
\hline Build & $16 \mathrm{X}$ & $13 \mathrm{X}-16 \mathrm{X}$ & $7 \mathrm{X}$ \\
\hline Test & $21 \mathrm{X}$ & $61 \mathrm{X}-78 \mathrm{X}$ & $28 \mathrm{X}$ \\
\hline Operations & $29 \mathrm{X}$ & $157 \mathrm{X}-186 \mathrm{X}$ & $1615 \mathrm{X}$ \\
\hline
\end{tabular}

\section{Table 12: Comparison of Methods 1, 2, \& 3 Cost Factors}

First we will examine the similarities in the results. If the operations phase was to be disregarded, the results would be as shown in Figure 3. There is a high degree in similarity between the results when viewed from this perspective. It shows that escalation in the cost to fix errors is a real phenomenon, and that it can affect both large and small projects. The data also shows that the escalation in cost is an exponential function.

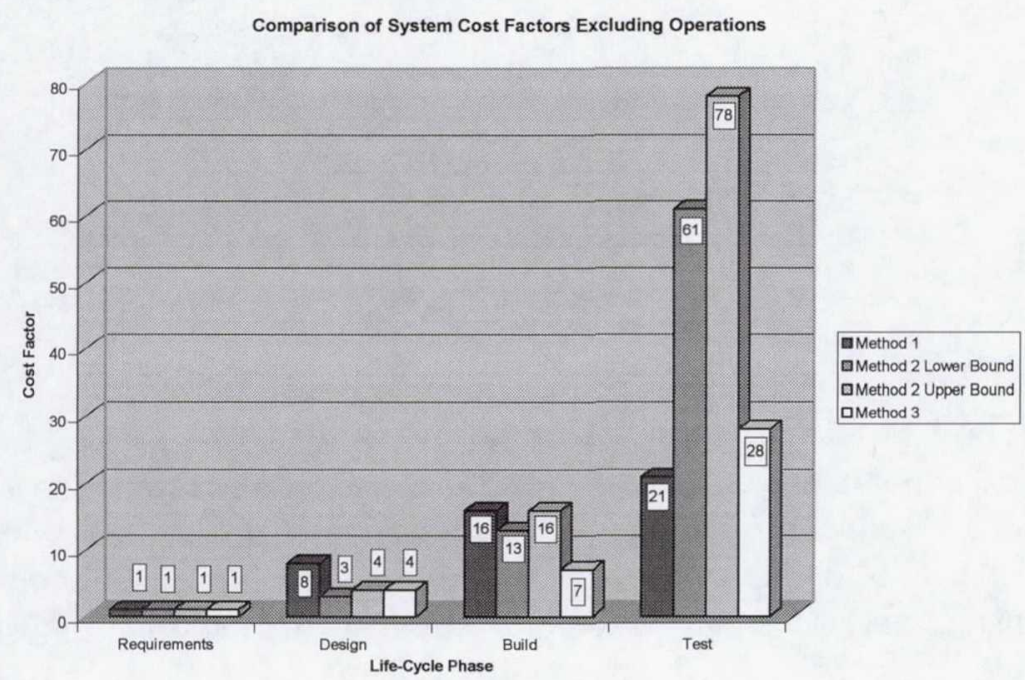

Figure 3. Comparison of Methods $1,2, \& 3$ Cost Factors Without Operations Phase 
The results are also dissimilar in many ways. For example, methods two and three clearly do not give the same factors for the last three phases. Part of this can be explained by the nature of the errors used in method three. All of those errors were of such magnitude that if they were not discovered prior to the Operations phase, they would result in a loss of the entire system. Table 13 compares the cost factors for software projects with those for systems projects; the systems cost factors shown are a composite of the results of the three methods used in this study. The comparison is shown graphically in Figure 4.

\begin{tabular}{|l|c|c|}
\hline & $\begin{array}{c}\text { Software } \\
\text { Cost Factors }\end{array}$ & $\begin{array}{c}\text { Systems } \\
\text { Cost Factors }\end{array}$ \\
\hline Requirements & $1 \mathrm{X}$ & $1 \mathrm{X}$ \\
\hline Design & $5-7 \mathrm{X}$ & $3 \mathrm{X}-8 \mathrm{X}$ \\
\hline Build & $10 \mathrm{X}-26 \mathrm{X}$ & $7 \mathrm{X}-16 \mathrm{X}$ \\
\hline Test & $50 \mathrm{X}-177 \mathrm{X}$ & $21 \mathrm{X}-78 \mathrm{X}$ \\
\hline Operations & $100 \mathrm{X}-1000 \mathrm{X}$ & $29 \mathrm{X}-1615 \mathrm{X}$ \\
\hline
\end{tabular}

Table 13: Comparison of Software \& Systems Cost Factors

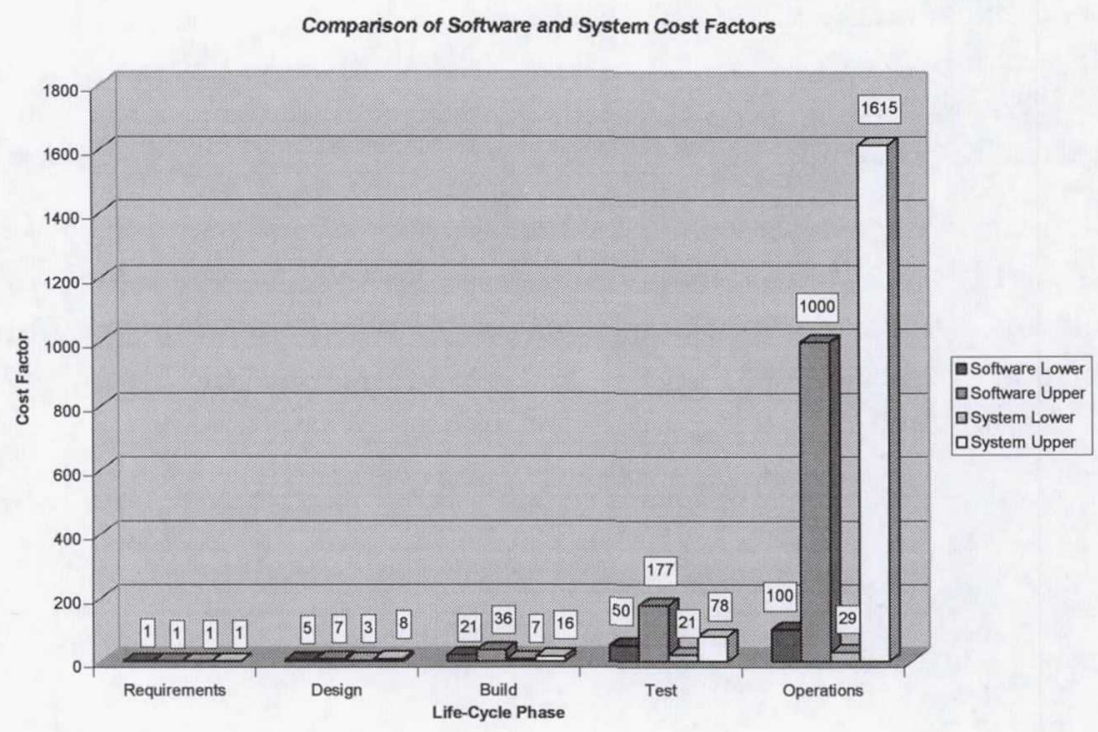

Figure 4. Comparison of Software and Systems Cost Factors

Again, there are both similarities and differences to be seen in this cost data. The software costs follow the same exponential trend as the systems costs. This is not surprising as in many respects software and systems are developed similarly. In addition, the upper bound of the software operations phase cost factor is of the same order as the upper bound of the systems operations phase cost factor. This would seem to indicate that software systems are just as vulnerable to so called "killer errors", as are physical systems. 


\section{Recommendations}

There are areas that could be improved upon in follow-on studies. First, with respect to methods one and two, a greater sample size would clearly improve the accuracy of the results. The data used in this study was somewhat limited in quantity and with respect to the details of the errors involved. A future study could benefit from a larger sample size, and a greater depth of knowledge concerning the errors to be analyzed. Another improvement that could be made is with respect to the types of projects from which the data is collected. The real-world data used in this study came from two large aerospace projects.

Future studies could examine data from both smaller aerospace projects and projects from other sources such as the telecommunications, construction, and petrochemical industries. This would give the resultant cost factors a much broader applicability. With respect to method three, future studies could also make improvements. First, the model should be validated by comparison with actual errors. The model source data - including the cost estimating relationships - could be improved through this validation process.

\section{Summary}

This paper presents the results of a study on the escalation of the cost to fix errors as a project moves through its life cycle. The team used three methods to calculate the escalation in costs: the bottom-up cost method, the total cost breakdown method, and the top-down hypothetical project method. In each of the methods, the costs were normalized to obtain cost factors. The study revealed that costs escalate in an exponential fashion. This paper demonstrates that early detection of errors is highly important to the success of any project.

\section{References}

Boehm, B. W., Software Engineering Economics, Prentice-Hall, Englewood Cliffs, NJ, 1981.

Cigital, "Case study: Finding defects earlier yields enormous savings," Available at www.cigital.com, 2003.

Cloud, Giffen, Larson, and Swan, "Designing Cost-Effective Space Missions: An Integrated, Systems Engineering Approach," Teaching Science and Technology, Inc., 1999.

Larson, W. and Wertz, J., Space Mission Analysis and Design, Second Edition, Microcosm, Inc. and Kluwer Academic Publishers, Boston, 1993.

MATLAB, Learning MATLAB, The MathWorks, Inc., January 2001.

McGibbon, T., "Return on investment from software process improvement," Available at www.dacs.dtic.mil, 2003.

Mortice Kern Systems Inc., "From Software Quality Control to Quality Assurance," 2001.

NASA Systems Engineering Handbook, SP-6105, National Aeronautics and Space Administration, June 1995.

Pavlina, S., "Zero-defect software development," Dexterity Software, Available at www.dexterity.com, 2003.

Rothman, J., "What does it cost to fix a defect?" StickyMinds.com, February 2002, Available at http://www.stickyminds.com/stqeletter/archive/20020220nl.asp, 2003.

Schneider, G. M., Martin, J., and Tsai, W. T., "An experimental study of fault detection in user requirements documents," ACM Transactions on Software Engineering and Methodology, Vol 1, No 2, April, 1992, pp 188-204. 